\title{
TC
}

\section{Tobacco in prisons: a focus group study}

R Richmond, T Butler, K Wilhelm, et al.

Tob Control 2009 18: 176-182 originally published online February 2, 2009 doi: 10.1136/tc.2008.026393

Updated information and services can be found at:

http://tobaccocontrol.bmj.com/content/18/3/176.full.html

These include:

References This article cites 24 articles, 6 of which can be accessed free at: http://tobaccocontrol.bmj.com/content/18/3/176.full.html\#ref-list-1

Email alerting Receive free email alerts when new articles cite this article. Sign up in the service box at the top right corner of the online article.

Notes

To order reprints of this article go to:

http://tobaccocontrol.bmj.com/cgi/reprintform

To subscribe to Tobacco Control go to:

http://tobaccocontrol.bmj.com/subscriptions 


\title{
Tobacco in prisons: a focus group study
}

\author{
R Richmond, ${ }^{1}$ T Butler, ${ }^{2,3}$ K Wilhelm, ${ }^{4,5}$ A Wodak, ${ }^{5}$ M Cunningham, ${ }^{1}$ I Anderson ${ }^{6}$
}

${ }^{1}$ School of Public Health and Community Medicine, University of New South Wales, Sydney, New South Wales, Australia; ${ }^{2}$ Centre for Health Research in Criminal Justice, (NSW Justice Health), Sydney, New South Wales, Australia; ${ }^{3}$ National Drug Research Institute, Curtin University of Technology, Perth, Western Australia, Australia;

${ }^{4}$ School of Psychiatry, University of New South Wales, Sydney, New South Wales, Australia;

${ }^{5}$ St Vincent's Hospital, Darlinghurst, New South Wales, Australia; ${ }^{6}$ Centre for Health and Society, Onemda VicHealth Koori Health Unit, University of Melbourne, Victoria, Australia

Correspondence to: Professor Robyn Richmond, School of Public Health and Community Medicine, University of New South Wales, 2052, Australia; R.Richmond@unsw. edu.au

Received 4 June 2008 Accepted 6 January 2009 Published Online First 2 February 2009

\author{
ABSTRACT \\ Objective: To examine the role of tobacco use in prison \\ and possible influences of the prison environment on \\ smoking among inmates in the context of developing \\ inmate smoking cessation programmes.
}

Method: Qualitative study based on seven focus groups with prisoners and ex-prisoners.

Settings: A maximum security prison in rural New South Wales (NSW), Australia, and a community justice restorative centre and accommodation service for exprisoners in Sydney, NSW, Australia.

Participants: 40 participants (28 men and 12 women) comprising nine prisoners (including four Indigenous inmates) and 31 ex-prisoners.

Results: Prisoners reported that tobacco serves as a de facto currency in correctional settings and can be exchanged for goods, used to pay debts and for gambling. Smoking helps manage the stressful situations such as transfers, court appearances and prison visits. Inmate smoking cessation programmes need to address the enmeshment of tobacco in prison life, improve availability of pharmacotherapies (for example, nicotine patches, bupropion) and the quitline (a free telephone helpline providing information on stopping smoking), provide nonsmoking cells and areas within prisons, encourage physical activity for inmates and maintain monitoring of smoking cessation status after release.

Conclusions: Tobacco is integrally bound up in the prison "culture". Our findings are relevant to inform prison health authorities concerned with improving the health of prisoners, and for support organisations attempting to facilitate smoking cessation both in prison and after release. Smoking cessation programmes in prisons should be tailored to the unique stresses of the prison environment. Programmes need to acknowledge the difficulties of quitting smoking in prison arising from the stresses posed by this setting.

Currently $16.6 \%$ of Australians are daily tobacco smokers (18\% of males and $15 \%$ of females). ${ }^{1} \mathrm{~A}$ range of primary and secondary prevention tobacco control strategies has resulted in a steady decline in tobacco use since the middle of the last century with a corresponding reduction in chronic diseases in the general Australian population. ${ }^{2}$

Disadvantaged people and those from lower socioeconomic groups generally have poorer health than the rest of the community, endure a higher burden of disease $e^{3}$ and engage in unhealthy lifestyles (for example, smoking, physical inactivity, overweight). ${ }^{4}$ Tobacco use is a major risk factor for cardiovascular disease, many cancers, ${ }^{5}$ diabetes and pulmonary disease. ${ }^{6}$ These health effects are gradually reversed after cessation of smoking. ${ }^{7}$

Prisoner populations have a smoking prevalence that is over three times that of the general population (estimates range from $78 \%$ to $83 \%)^{8}$ and is rising ${ }^{9-11}$ with younger prisoners (those under 25 years of age) more likely to smoke than older inmates aged 40 years and older $(86 \%$ vs $64 \%){ }^{11}$ One study found that ex-prisoners are more likely to die of tobacco-related cancers than the general community. ${ }^{12}$ Similar findings have been reported in UK studies where $89 \%$ of prisoners smoked before incarceration ${ }^{13} 14$ and $79 \%$ prisoners reported smoking in a Scottish study. ${ }^{14} 15$ In the United States, "the great majority" of inmates smoke in prison. ${ }^{16}$

Certain population groups are known to have a higher smoking prevalence than the general population and these groups are also over-represented among prisoners. ${ }^{14} 17-19$ They include people with a mental illness (smoking prevalence 62\%), ${ }^{20}$ Indigenous Australians (50\%) ${ }^{421}$ and illicit drug users (71\%). ${ }^{22}$ Tobacco smoking was responsible for $12 \%$ of the total burden and one-fifth of deaths in Indigenous Australians in 2003. ${ }^{23}$ Further, prisoners are generally from disadvantaged backgrounds and often have had poor education, a history of neglect, being placed in care or experience of juvenile detention. ${ }^{9}$

Prisoners, like other marginalised groups, are less likely to attend community-based smoking cessation and health promotion programmes ${ }^{24}$ after prison and consequently have a disproportionate burden of tobacco-related diseases. ${ }^{12}$ One possible reason is the absence of interventions developed specifically for these population groups and feelings of marginalisation in mainstream settings. ${ }^{25}$ There is a pressing need for smoking cessation programmes that specifically target those at high risk ${ }^{14}{ }^{25}$ and those described as "hidden" populations. ${ }^{26}$ Improving and increasing quit smoking services for groups with a high prevalence of smoking is justified on both equity and public health grounds. To this end, the New South Wales correctional system restricts smoking to cells and designated smoking areas ${ }^{11}$ and has a policy of not accommodating smoker and non-smoker inmates together.

We conducted focus groups with prisoners and ex-prisoners to understand the dynamics of tobacco smoking in prison and glean information that would assist in developing an effective smoking cessation intervention for prisoners.

\section{METHODS}

Seven focus groups were held: two were conducted in a men's maximum security prison in NSW and five at a community organisation providing social support services for ex-prisoners. This community organisation was based in an inner-city suburb, accessed by ex-prisoners across the entire city for post-prison community justice restorative programmes, as well accommodation services in the 


\section{Box 1: The function of tobacco use in prison}

- "The percent of smokers in jails are like 90 odd percent. And that's not counting all the prison officers smoking". (Male, exprisoner)

- "I did a 2 year stint in "segro" [referring to segregation from other prisoners] and smoking was the only thing that relieved my anxiety in my cell. I really looked forward to a cigarette. Cigarettes were like a drug". (Male, ex-prisoner)

- "Being locked up 15 hours a day-the only thing to do is smoke". (Male, prisoner)

12 weeks after prison. This meant that the focus groups were conducted with people in prison, within 12 weeks post-prison and with ex-prisoners 1-10 years after prison.

Focus groups were advertised using posters placed on notice boards calling for volunteers. The duration of each focus group was approximately 2 hours. Participants received \$AU30 to cover costs of meals (and travel expenses in the case of exprisoners) and to cover time and payment for prisoners working within the prison system. Participation in both settings was voluntary and confidentiality was assured. Written consent was obtained from all participants.

Custodial staff did not attend the prison-based focus groups. Security concerns precluded audio taping the prison-based focus groups and thus detailed notes had to be recorded by hand. The community-based focus groups were taped and then transcribed. Three team members were present in the prison focus groups: a facilitator (RR or MC), a prison nurse and an observer.

Ethics approval was granted by the University of New South Wales, NSW Justice Health and the NSW Department of Corrective Services human research ethics committees. Permission to carry out the prison-based focus groups was also provided by the general manager at the prison.

A semi-structured focus group schedule was developed by the team comprising a psychiatrist, two public health practitioners, a prisoner health researcher, a physician, an Indigenous medical

\section{Box 2: Tobacco as currency in prison}

- "Tobacco carries status like paper money. You have to pay your debts just like you have to do on the outside. If someone owes you $\$ 50$, then instead of paying you cash they give you tobacco". (Male, prisoner)

- "If you didn't have cash you use tobacco. It gets you the things you need. You can get anything with tobacco, as long as the seal isn't broken you're right". (Male, ex-prisoner)

- "If you haven't got 'White 0x' (a brand of loose tobacco in pouches to make "roll-your-own" cigarettes), you can"t do business". (Male, ex-prisoner)

- "Tobacco is like cash to use in trade as long as the pouch of tobacco is unopened". (Female, ex-prisoner)

- "Tobacco is used for protection in prison in the sense that if you pay your debts then trouble won't come your way". (Male, ex-prisoner)

- "Corrective Services has always had a beef about tobacco and accuse inmates of stockpiling tobacco. They call jail searches to see if you are stockpiling tobacco and if you've got more than 7 packets in your cell, they consider that you are trading". (Male, prisoner)

\section{Box 3: Tobacco as a control mechanism in prison}

- "Standover tactics are the major ways to get tobacco with stronger men taking it from younger men, or people of a different culture". (Male, prisoner, Aborigine)

- "Officers know that prisoners love their tobacco and they find ways to punish you. One bit of backchat and they get back at you. They muck about with your buy-up sheets (a list of items prisoners can legally purchase from the prison shop) and strike your tobacco out. I've seen guys miss out on the buy-up for 4 weeks in a row". (Male, prisoner, and male ex-prisoner)

- "The girls that were in the psych units were screaming and bashing their head against the walls. The prison officers said they would give them a smoke if they would shut up". (Female, ex-prisoners)

- "I've seen someone nearly get killed over a cigarette". (Male, ex-prisoner)

practitioner and an experienced focus group facilitator/ researcher. Key questions focused on reasons for commencing smoking, the role of tobacco in participants' lives, the role of smoking in prison culture, smoking cessation inside and outside prison and methods used to quit smoking.

Content analysis was done on the first series of focus groups where the focus of earlier work addressed the ways in which participants spoke about issues and the pauses and syntax in conversations. This was part of an earlier study that focused on the inmates. ${ }^{27}$ After completion of the later focus groups which focused on ex-prisoners, a thematic analysis was completed individually for each group, including a return to the earlier prisoner transcripts. This first-line analysis enabled the identification of themes specific to individual groups with different compositions. ${ }^{27}{ }^{28} \mathrm{~A}$ secondary level of analysis was conducted across all groups. In this way we were able to differentiate the themes for inmates, ex-prisoners (male) and ex-prisoners (female). We were also able to identify themes common across all groups and the major themes are presented below.

\section{RESULTS}

Forty people participated in the seven focus groups. The nine participants of the prison-based focus groups were male and included four Aboriginal prisoners. The five community-based focus groups comprised 31 ex-prisoners $(19$ males and 12 females). All women ex-prisoners attended a separate group. Participants ranged in age from their mid 20s to late 40s. In the prison groups and the immediate post-prison ex-prisoners all were current smokers. In the longer-term ex-prisoner focus groups only two people were still non-smokers since leaving prison. In the female ex-prisoner group there was one nonsmoker (had never smoked). In all groups (apart from the Aboriginal group) there was at least one participant who was a non-smoker before entering prison.

\section{The function of tobacco use in prison}

Inmate tobacco use is bound up in the routine of prison life (box 1). It was considered helpful in managing stress and relieving tension in prison and a comfort during transfers between facilities and when making court appearances. Inmates reported that smoking helped "manage the boredom" (box 1). Smoking was a marker of the prison routine and of marking time. The "smoko break" was even used by some prison officers when communicating with prisoners that it was time to break for 


\section{Box 4: Contribution of the prison system to smoking among prisoners}

- "When I first went to jail, you could smoke everywhere. But over the years they've brought in anti-smoking laws in government buildings. These days you can only smoke in your 'slot' (referring to the prison cell) or out in the oval. So the environment is a huge change. I've known people who have gone to jail and were non-smokers and taken up smoking. If you're a non-smoker, 'it' (referring to the prison environment) can cause you to smoke". (Male, ex-prisoner)

- "I went into reception waiting for my sentence and I wasn't smoking. Did it for 7 days, then come out and they give you the reception pouch (referring to the cigarettes that were given to him)". (Male, prisoner)

- "In some parts of prison there are places you can smoke in and places you can't. Even when there are places you can't smoke in, there are people smoking anyway. The rules don't stop them". (Male prisoner, Aborigine)

- "The design of prisons-I can smell the bloke downstairs in my cell. I can smell it when he lights up. The prison officers smoke - walking past, checking, smell comes through the locks, you wake up to the smell of tobacco smoke in your cell". (Male prisoner)

- "The biggest barrier is how many people in prison smoke among both prisoners as well as officers". (Male prisoner and female ex-prisoner)

meals. Most participants commenced smoking before entering prison, usually in childhood and thought that smoking made them look "cool", "sophisticated" and "outdoorsy". Tobacco use was bound up with other substance use such as drinking alcohol and snorting cocaine. Some prisoners initiated tobacco use as an alternative to using drugs in prison-one commented that when in prison "it's the only drug left". Participants commented on the relation between the quantity of tobacco smoked and their security classification-those held in maximum security tend to spend longer periods each day locked in their cells.

\section{Tobacco as currency in prison}

Participants commented on the importance of tobacco as a de facto currency in the prison economy (box 2). Unopened packs of tailor-made cigarettes were the prison equivalent of cash providing exchange for goods (such as food and drugs) and to pay debts. Lankenau also found this in US prisons where smoking was allowed. ${ }^{16}$

\section{Tobacco as a control mechanism in prison}

Participants reported that tobacco was used to respond to "standover" tactics and bullying by other prisoners, as well as in the context of punishment (box 3). All participants raised the issue of restricted access to cigarettes during court appearances and while in isolation. Some female participants claimed that tobacco was sometimes used as a "reward" to stop disruptive behaviour, tantalise and tease prisoners, and as a means of calming them down during a crisis.

\section{Contribution of the prison system to smoking among prisoners} Older participants mentioned the previous policy of paying for prison work with tobacco and issuing new prisoners with tobacco at reception irrespective of whether or not they smoked. Quitting is complicated by the prevalence of smokers in their environment (box 4).

\section{Strategies used for smoking cessation while in prison}

Many participants reported previous quit attempts in prison noting the contribution of stress and prison system routines in the difficulties they experienced quitting smoking. They acknowledged that encouragement from family members helped their quit attempts in prison (box 5). Some considered that nicotine patches were unhelpful and too costly (NSW prisoners must purchase their own patches; a week's supply of patches costs only marginally less than a corresponding supply of cigarettes). Nicotine patches were considered less effective than the use of willpower. Men in particular noted the importance of physical exercise to replace smoking behaviour (box 5). When a prison went on "lock-down" (that is, people stayed in cells all day and other activities were disbanded because of security breaches) it was a particular trigger point to resumption of smoking behaviour. Others thought that they would quit if patches and other pharmacotherapies (such as bupropion) were available free. Most wanted help to prepare a cessation plan with defined goals. Exercise was considered to be a helpful alternative to smoking. Female participants noted

\section{Box 5: Strategies used for smoking cessation while in} prison

- "Friend of mine was going to be out in six months and his wife had given him an ultimatum. If you're still smoking when you get out, you're not coming home. Yeah, and he had two kids as well. So he just slowly cut down and sort of quit smoking in the last months of prison. So there were no cravings when he got out". (Male, prisoner)

- "I hadn't smoked for 7 years. Then I took it up, then realised my mum was dying of emphysema and that was the reason I gave it away. Because I wasn't gonna go the way she went". (Male, ex-prisoner, non-smoker)

- "Jeez those patches are expensive. 20 bucks" (\$40 for a box). (Male, ex-prisoner)

- "I think them patches are good". (Female, ex-prisoner)

- "Many of the guys in here are very strong willed, directional, so teach them goals and how to get there". (Male, prisoner)

- "Well I gave up once... and did it cold turkey; I just stopped and didn't have another one. Think that's the way to do it. The faster you get that nicotine out of your system, the easier it is". (Male, ex-prisoner, non-smoker)

- "For 6 months I done it while I was in jail and every day I was biting the bullet and just wanting a cigarette. I'd lock myself in me room without cigarettes, without an ashtray. It was temptation during the day, so I put myself into training (referring to the gym)". (Male, ex-prisoner)

- "One of my mates starting substituting smokes with exercise, and started training. He done alright for 12 months, but then threw it in and started smoking again. Stopped training. It's stress". (Male, ex-prisoner)

- "It's too stressful in jail to give up cigarettes". (Male and female ex-prisoner)

- "I suppose if they wanted to they could team up with a nonsmoker if they want to quit". (Male, prisoner, Aborigine)

- "They ought to have their own wing' [referring to smokers]. (Male prisoner and female ex-prisoner)" 


\section{Box 6: Attitude to changing smoking behaviour in prison}

- "I would hate it if you could not smoke...yea, you'd have girls punching up". (Female, ex-prisoner)

- "There would be riots, there would be all sorts of bloody things". (Male, ex-prisoner)

- "It would turn the jail system on its ear". (Male, ex-prisoner)

- "It makes me feel suicidal if I try to give up". (Male, prisoner)

- "A very obvious question is you are in there for a crime, not to be punished for your smoking". (Male, ex-prisoner)

- "I've heard of people suing prisons twice because of smoking. But you know taking smokes off guys who've been smoking all their life, there's nothing worse. Taking it off them would be wrong". (Male, ex-prisoner)

- "I've been in police cells in different places and they help you with patches for free". (Female, ex-prisoner)

- "They are just so stressed out. But if the system turned around and said-look if you want to go on a programme... If they supplied the cigarette patches and all the associated paraphernalia I would certainly have a go at that". (Male, prisoner)

limitations with the current telephone counselling service for smokers (called the "quitline" in Australia) and recommended they receive information on the availability of quitline services for prisoners. There was a view that smoking cessation was not considered a priority by prison authorities with most attention directed at other alcohol and drug problems.

One prison focus group discussed a goal-oriented approach to quitting smoking based on small steps and suggested the development of a quitting calendar. This discussion occurred spontaneously in the group after prisoners had identified whether they had seen some specific smoking cessation audiovisual aids. In ex-prisoner focus groups the suggestions made by the prison focus group were checked for their perceptions of usefulness in a prison setting. There was general agreement that prisons should offer voluntary smoking cessation programmes including incentives such as provision of separate accommodation for those giving up smoking. The focus groups highlighted the poor knowledge of smoking cessation strategies among inmates; some had not heard of bupropion, would not consider approaching a doctor for assistance and would not attend specific smoking cessation programmes when in the community.

\section{Attitude to changing smoking behaviour in prison}

Concerns were expressed about mooted changes in the prison system to restrict or ban tobacco smoking and about prisoners' rights to smoke and tobacco's role in maintaining the status quo and limiting violence. Reducing smoking in prison was considered likely to increase tension and violence (box 6). Some Aboriginal prisoners thought that savings from not smoking could be used to purchase more art materials. In our pilot study prices for art supplies available to prisoners were expressed in numbers of cigarettes. Paintings by the inmates are sold in the prison shop and the inmates receive the purchase price minus the cost of the materials.

The prisoners suggested a range of practical strategies to assist with smoking cessation in the correctional system including smoke-free areas, incentives, subsidised pharmacotherapy, clinic support and educational materials. Participants also identified

\section{Box 7: Role of smoking and cessation after prison}

- "I've moved on to a bong (referring to cannabis). I know it stops me from smoking "bungers" (referring to cigarettes)". (Male, ex-prisoner)

- “The big difference is you've got freedom outside. You don't have to hold onto your smoke and have to carry it everywhere...cos you're afraid someone's gonna steal it". (Female, ex-prisoner)

reasons for relapse and barriers to quitting, which emphasised the specific stresses and tensions of prison life.

\section{Role of smoking and cessation following release from prison}

The majority of participants reported continuing to smoke following release from prison. Some continued to smoke the loose tobacco used to roll-your-own cigarettes commonly used in prison while others reverted to more conventional tailormade cigarettes. Some men reported smoking fewer cigarettes because of reduced stress and fewer demands but others said they smoked less because they had substituted nicotine with other drugs (box 7). Male and female participants reported appreciating the freedom to smoke outside prison and not having to protect and ration cigarettes. However, some women who had been incarcerated for longer periods found adjusting back to community life especially challenging and reported smoking more and increasing their drug use following release from prison.

\section{DISCUSSION}

The specific social and cultural context of prisons has its own normative values, processes and social relationships. Tobacco use needs to be better understood in the prison environment to ensure that more effective and appropriate smoking cessation interventions can be developed for inmate populations. The prevalence of smoking in prison populations is far greater than in the general population, ${ }^{4}$ a finding also noted in studies in the United Kingdom. ${ }^{14}$ Reducing the prevalence of smoking among prisoners may not only improve their health but also increase their meagre savings, assist efforts to control their often problematic consumption of other drugs while also assisting efforts by authorities to provide a healthier working environment for prison staff. A pilot study conducted among male inmates at a maximum security prison in New South Wales found that a smoking cessation intervention in prison was feasible, acceptable to prison inmates and effective. ${ }^{29}$

\section{Characteristics of the prison setting and smoking}

This qualitative investigation highlights a range of issues including the variety of roles that tobacco has in the prison system, the institutional context of smoking in prison and prisons as a setting for smoking cessation. Indigenous and nonIndigenous prisoners and current and ex-prisoners had similar views regarding the critical importance of the institutional context of tobacco in prison on the values and social processes of smoking.

Tobacco has been commonly regarded as a currency in prisons worldwide for decades and cigarettes are used to settle payments for gambling, illicit drugs, other goods and services. ${ }^{16} 30$ Tobacco is also used to pay for "protection" from standover tactics and bullying. Intimidation was reported to be 
prevalent with "stronger men taking tobacco from younger men, or people from a different culture".

Certain characteristics of prisons may encourage smoking and also reduce the effectiveness of smoking cessation interventions. The majority of participants in this study reported smoking more heavily in prison than when in the community. A recent study of prison inmates in NSW, Australia found that $41 \%$ of respondents reported smoking more heavily in prison than when living in the community. ${ }^{11}$ Smoking is widely regarded as "normal" in prison. Most prisoners were smokers before entering prison although in each focus group participants said they knew of inmates who commenced smoking while incarcerated. Belcher et al reported that only $7 \%$ of smokers in NSW prisons commenced tobacco use after incarceration. ${ }^{11}$

The prison environment is extremely limiting with few social options. Boredom, stress, anxiety related to legal matters, the impact of being locked in a cell for up to 15 hours each day ${ }^{31}$ and social isolation all increase the likelihood that inmates will smoke. Reports of smoking ${ }^{32}$ being used as a reward in mental health and drug and alcohol treatment settings seem to have a parallel function in prison. Prisoners reported that they had few alternatives to smoking. This finding has also been reported in UK prisons where pressures to smoke are stronger in prison than in the community. ${ }^{14}$

In this study prisoners suggested a range of practical strategies to assist with smoking cessation in the correctional system. These included offering smoke-free cells or prison wings, providing incentives for non-smokers, providing ready access to free (or low-cost) nicotine patches and bupropion, provision of support for quitting from the prison clinic and prison officers and being allowed to have educational materials in their cells. Attention needs to be focused on provision of healthy and interesting alternatives to smoking, including enabling regular exercise, creative outlets, improving stress management, interpersonal skills and education to improve rehabilitation and decrease aggression and drug taking.

One prison-based focus group developed a specific goaloriented calendar that became a valuable resource in the multicomponent smoking cessation intervention that we provided to prisoners. Women prisoners recommended alternative approaches such as acupuncture, hypnosis and the provision of more information on how to use the quitline.

\section{Smoking cessation and healthy lifestyle changes}

We were pleasantly surprised by the inmates' focus on healthy lifestyle activities. A previous finding by one author that most inmates who smoke want to quit, ${ }^{33}$ resonates with others' conclusions. ${ }^{14}$ Half reported attempting to stop smoking or reduce their tobacco consumption in the previous year, while $23 \%$ of men and $13 \%$ of women planned to quit smoking within the next 3 months. ${ }^{11}$ We also found that most (95\%) who had relapsed during the pilot study wanted to try to quit again using our multi-component smoking cessation programme. ${ }^{29}$

A study in NSW jails reported that two-thirds of prisoners had exercised for at least 30 minutes per day for the previous 4 weeks while $62 \%$ were interested in the nutritional value of prison food. ${ }^{9}$ Focus group participants referred to exercise as a substitute for smoking and were very positive about physical activity.

Participants identified reasons for relapse and barriers to quitting that emphasised the specific stresses and tensions of prison life. A common trigger for relapse is transfer to another wing or prison which is a particularly stressful event. ${ }^{29}$ There are an estimated 140000 prisoner movements within NSW prisons every year, suggesting that this may be an important impediment to efforts to quit smoking, particularly for individuals in the middle of a cessation programme. These prisoner transfers are required for a variety of reasons including court appearances, to ensure a prisoner's safety, to locate the inmates closer to their family, medical appointments and attending community events. Other barriers to quitting include bullying, missing family and prolonged periods of isolation while locked in cells. These factors have been identified in the United Kingdom ${ }^{14}$ and were also noted in our pilot study where we responded to them by developing specific interventions to improve life skills in dealing with change and stress. ${ }^{29}$

Ex-prisoners recommended that after release, smoking cessation services could be offered (at no cost) through the agencies supporting them in the community rather than requiring attendance at mainstream smoking cessation clinics. Participants suggested offering smoking cessation programmes in juvenile justice settings. As inmates rarely attend smoking cessation services in the community, ${ }^{33}$ offering such programmes and other healthy lifestyle promoting activities in prison and among ex-prisoner groups in the community is a way of increasing the equity of health outcomes in this group.

\section{Human rights of prisoners}

Attempts to introduce smoking bans in prison have been delayed in some jurisdictions in Australia by legal arguments that a prisoner's cell constitutes their "home" 34 and thus supports their right to smoke. Although the NSW prison smoking policy restricts smoking to cells and designated smoking areas, ${ }^{11}$ and has a policy of not accommodating smoker and non-smoker inmates together, a 2001 survey of prisoners found that one-third of non-smokers shared a cell with a smoker. ${ }^{11}$ These arguments need to be balanced against the human right for conditions leading to good health for smoking and non-smoking prison inmates and staff.

Some prisoners were fearful of a future smoking ban. Participants referred to "turning the jail system on its ear" if they were prevented from smoking. Niesche describes a prison riot in Queensland (Australia) attributed in part to a prison "non-smoking" ban. ${ }^{35}$ This suggests that imposing smoking restrictions and bans in prison need to be managed appropriately. Given the high level of interest in and support for smoking cessation among inmates, ${ }^{11}$ it may be worth targeting opinion leaders among those who are against the restrictions and bans to enable a smoother transition.

Concerns about adverse effects of smoking bans need to be balanced against the rights of prisoners wishing to be in a smoke-free environment. Further, while smoking bans have a clear role in many public settings such as restaurants, hospitals and workplaces, prisons have their own idiosyncratic problems associated with prohibition such as smuggling, trading and black market opportunities. ${ }^{16}{ }^{36}$ Over a decade ago, Patten et al discussed the feasibility of psychiatric and chemical dependency units becoming smoke free. They noted the need for interventions directed at staff and patients and commented "we are observing a tremendous amount of self-reported anger, depression and other "emotional" symptoms as most (90\%) of the patients are smokers and highly addicted to nicotine". ${ }^{37}$

Participants noted that more services and support were available for inmates with alcohol and heroin dependence than was being offered to smokers. This is in accordance with NSW Department of Corrective Services policy in which the focus of programmes is on behaviours associated with re-offending particularly illicit drug use and alcohol consumption. 
Treatment providers commonly regard smoking as a lesser problem than mental disorders or other drug and alcohol dependencies. ${ }^{38}$ These attitudes may undermine efforts to treat smokers. ${ }^{39}$ Tobacco smoking needs to be given the same (or more) attention as other addictive drugs and mental health problems and is best done in concert with these other approaches where there is co-morbidity.

The high prevalence of smoking among prison staff may also undermine smoking cessation efforts among inmates. ${ }^{40-42}$ Prison officers should be encouraged to quit smoking by attending a general practitioner in the community who can provide advice and information on available pharmacotherapies or quitlines. A study of prison employees found that they supported an indoor smoking ban but opposed a total ban or restrictions on their own smoking. ${ }^{43}$ These findings indicate the scope of the problems and some of the barriers. There is much to be done to reduce the level of smoking among prison inmates towards prevalence in the rest of the community.

\section{Limitations of the study}

A limitation of this qualitative study includes a possible selection bias arising from the fact that participants selected themselves rather than being randomly selected. ${ }^{44}$

The main limitation of this study is the use of limited numbers of participants and the generalisability of their comments to the wider prisoner population. Selection bias is another possibility arising from self-selection rather than random selection.

In six of the seven focus groups there were social and gender differences between the researchers (all women) and the prisoners (all men). This may have led to an under-representation of the female participants' views. However, we analysed areas of concordance within and across focus groups to reduce this bias. ${ }^{45}$ We also compared findings from prisoners with exprisoners to reach a balanced and representative view of smoking in prison. ${ }^{46}$

Current prisoners may have been unwilling to divulge information putting them at risk from either other prisoners or prison officers. However, as ex-prisoners were less likely to be similarly constrained in their comments, we believe that we were able to obtain a wider range of responses. Participants were aware that there were not required to substantiate any of their claims and that there would be no reprisals if they provided erroneous information.

We were unable to authenticate information provided by any of the participants. It is also possible that participants did not restrict their comments to their own experiences.

\section{CONCLUSION}

We have examined the role of tobacco use in prison and found tobacco is integrally bound up in the culture of prison life. The material from our focus groups has highlighted issues relevant to the prison context and can continue to inform the development of a specifically targeted cessation programme for prisoners. This paper builds on previous research on the prevalence of smoking among prisoners and the information gained from the focus groups enabled us to develop an intervention for smoking cessation in the prison setting (currently under way). This paper adds unique information that can be used by clinicians to develop effective smoking cessation strategies for this marginalised and vulnerable population. Incarceration is an important public health opportunity for initiating smoking cessation programmes among a target group who do not access mainstream smoking cessation programmes nor regularly consult with a general practitioner. Our findings can also assist organisations to support inmates following their release to facilitate smoking cessation activities. Smoking cessation programmes in prison need to be tailored to the unique prison environment and the stressors of the postprison environment.

Acknowledgements: This study was funded by the National Heart Foundation of Australia and the NSW Department of Health. We appreciate the efforts of Dr Rowena Ivers who conducted the focus group of Aboriginal and Torres Strait Islander prisoners and Ms Elizabeth Baxter, research assistant, who organised and participated in the focus groups at Lithgow Correctional Centre. We are grateful to the NSW Department of Corrective Services, particularly general manager Mr Dave Tawhara, and the custodial officers at Lithgow Correctional Centre who supported the running of the focus groups. We are grateful to Mr Luke Grant (NSW Department of Corrective Services) and Ms Devon Indig (NSW Justice Health) who commented on the draft.

Competing interests: None.

\section{REFERENCES}

1. Australian Institute of Health and Welfare 2008. 2007 National drug strategy household survey: first results. Drug Statistics Series number 20. Cat no PHE 98. Canberra: AlHW.

2. Taylor R, Dobson A, Mirzaei M. Contribution of changes in risk factors to the decline of coronary heart disease mortality in Australia over three decades. Eur J Cardiovasc Prev Rehabilitation 2006;13:760-8.

3. Suhrcke M, Nugent R, Stuckler S, et al. Chronic disease: an economic perspective. Oxford: Health Alliance, 2006.

4. Australian Bureau of Statistics. National Health Survey: summary of results, 20042005. Cat No 4364.0. Canberra: ABS, 2006.

5. Lopez AD. Epidemiologic surveillance of the tobacco epidemic. MMWR Morb Mort Weekly Rep 1992;41(suppl):157-66.

6. Australian Institute of Health and Welfare. Chronic diseases and associated risk factors in Australia, 2006. Canberra: AlHW, 2006

7. Dresler CM, Leon ME, Straif $\mathrm{K}$, et al. Reversal of risk upon quitting smoking. Lancet 2006;368:348-9.

8. Butler T, Papanastasiou C. National prison entrants' bloodborne virus and risk behaviour survey report 2004 and 2007. National Drug Research Institute (Curtin University) and National Centre in HIV Epidemiology and Clinical Research (University of New South Wales). 2008.

9. Butler T, Milner L. The 2001 New South Wales inmate health survey. Sydney, NSW Corrections Health Service, 2003.

10. Hockings B, Young M, Falconer A, et al. Queensland women prisoners' health survey. Brisbane: Queensland Department of Corrective Services, 2002.

11. Belcher JM, Butler T, Richmond RL, et al. Smoking and its correlates in an Australian prisoner population. Drug Alcohol Rev 2006;25:343-8.

12. Kariminia A, Butler $\mathrm{T}$, Corben $\mathrm{S}$, et al. Extreme cause specific mortality among adults who have served time in prison: A cohort study. Int J Epidemiol 2007;36:3106.

13. HM Prison Service. 2007. Smoke free legislation: prison service application. Prison Service Instruction 09/2007.

14. MacAskill S, Lindridge A, Stead M, et al. Social Marketing with challenging target groups: smoking cessation in prisons in England and Wales. Int J Nonprofit Volunt Sect Mark 2008;13:251-61.

15. Scottish Prison Service (SPS). Prisoner survey. 2007 http://www.sps.gov.uk// MultimediaGallery/b662de7f-c9b3-41c6-a14b-e793340c27f0.pdf (20 October, 2008)

16. Lankenau SE. Smoke 'em if you got 'em: cigarette black markets in US prisons and jails. The Prison Journal 2001;81:142-61

17. Australian Bureau of Statistics. Prisoners in Australia. Canberra: ABS, 2004 (b).

18. Butler T, Allnutt S. Mental illness among New South Wales prisoners. Sydney: NSW Corrections Health Service, 2003.

19. Butler T, Allnutt S, Cain D, et al. Mental disorder in the New South Wales prisoner population. Aust NZ J Psychiatry 2005;39:407-13.

20. Davidson S, Judd F, Jolley D, et al. Cardiovascular risk factors for people with mental illness. Aust NZ J Psychiatry 2001;35:196-202.

21. Trewin D, Madden R. The health and welfare of Australia's Aboriginal and Torres Strait Islander peoples, 2003. Australian Bureau of Statistics cat No 4704.0. Canberra: Australian Bureau of Statistics, 2003.

22. Richter KP, Ahluwalia HK, Mosier MC, et al. A population-based study of cigarette smoking among illicit drug users in the United States. Addiction 2002;97:861-9.

23. Vos T, Barker B, Stanley L, et al. The burden of disease in Aboriginal and Torres Strait Islander peoples 2003. Brisbane: School of Population Health, University of Queensland, 2007:55.

24. Australian Institute of Health and Welfare. Australia's health 2002. Canberra: AlHW, 2002.

25. Baker A, Ivers RG, Bowman J, et al. Where there's smoke, there's fire: high prevalence of smoking among some sub-populations and recommendations for intervention. Drug Alcohol Review 2006;25:85-96. 
26. Duncan DF, White JB, Nicholson T. Using internet-based surveys to reach hidden populations: case of nonabusive illicit drug users. Am J Health Behav 2003;27:20818.

27. Richmond RL, Butler T, Belcher JM, et al. Promoting smoking cessation among prisoners: feasibility of a multi-component intervention. Aust NZ J Public Health 2006; 30:474-8.

28. Vaughn S, Shay Schumm J, Sinagub J. Focus group interviews in education and psychology. London: Sage, 1996.

29. Sim J. Collecting and analyzing qualitative data: issues raised by the focus group. $J$ Adv Nurs 1997;28:345-52.

30. Steering Committee for the Review of Government Service Provision. Report on government services 2005. Canberra: Productivity Commission, 2005.

31. Radford R. The economic organisation of a POW camp. Economica 1945;35:189201. http://www.albany.edu/ mirer/eco110/pow.html (accessed 20 October, 2008)

32. Williams $\mathbf{J}$, Ziedonis $\mathbf{D}$. Addressing tobacco among individuals with a mental illness or an addiction. Addict Behav 2004;29:1067-83.

33. Butler T, Milner L. The 2001 inmate health survey. Sydney, NSW: Corrections Health Service, 2003

34. Department of Corrective Services. Operations procedures manual. Smoke free environment policy. 22.25.2005. Sydney: NSW Department of Corrective Services, 2005.

35. Niesche C. Jails chief removed in wake of prison riot. Weekend Australian [newspaper], 1997; 18 April, page 7.
36. Butler T, Richmond R, Belcher J, et al. Should smoking be banned in prisons? Tob Control 2007:16:291-3.

37. Patten CA, Martin JE, Owen N. Can psychiatric and chemical dependency treatment units be smoke free? J Subst Abuse Treat 1996;13:107-18,

38. Bobo JK, Slade J, Hoffman AL. Nicotine addiction counseling for chemically dependent patients. Psychiatr Serv 1995;46:945-7.

39. Hurt RD, Croghan IT, Offord KP, et al. Attitudes towards nicotine dependence among chemical dependency unit staff-before and after a smoking cessation trial. J Subst Abuse Treat 1995; 12:247-52.

40. Harvey D, Tsey K, Cadet-James Y, et al. An evaluation of tobacco brief intervention training in three indigenous health care settings in north Queensland. Aust NZ J Public Health 2002;26:426-31.

41. Burling TA, Ramsey TG, Seidner AL, et al. Issues related to smoking cessation among substance abusers. J Substance Abuse 1997;9:27-40.

42. Olive $\mathbf{K}$, Ballard J. Attitudes of patients towards smoking by health professionals. Public Health Reports 1992;107:335-9.

43. Carpenter MJ, Hughes JR, Solomon LJ, et al. Smoking in correctional facilities: a survey of employees. Tob Control 2001;10:38-42.

44. Hennekens CH, Buring JE. Epidemiology in medicine. Boston: Little, Brown, 1987

45. Whitelaw S, Baxendale A, Bryce C, et al. "Settings" based health promotion: a review. Health Promot Int 2001;16:339-53.

46. Oppenheim AN. Questionnaire design, interviewing and attitude measurement. London: Pinter, 1992.

\section{The lighter side}
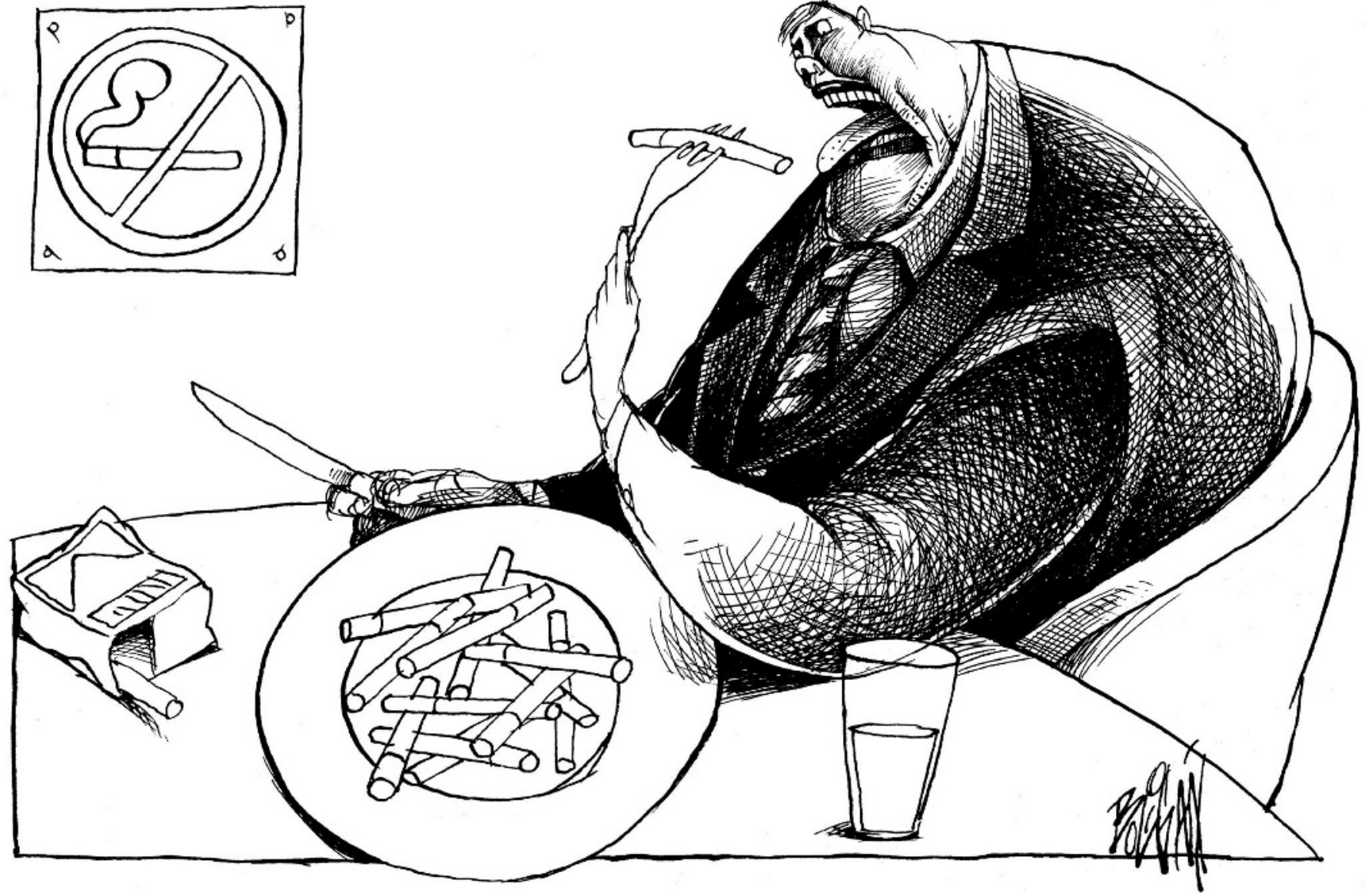

(c) 2008, Angel Boligan. All rights reserved. 